\title{
¿Qué tan plena es la acción de "plena" jurisdicción?
}

Pedro Harris Moya*

\begin{abstract}
Este comentario de jurisprudencia analiza la calificación de las acciones administrativas, a propósito de la Sentencia de Corte Suprema Sociedad Chamy con I. Municipalidad de Valparaíso (8 de octubre 2019), que distingue los ámbitos de aplicación del recurso de nulidad y de plena jurisdicción.
\end{abstract}

Palabras clave: Acción contenciosa, acción de nulidad, plena jurisdicción.
This case commentary analyses the qualification of administrative actions, with regard to the Supreme Court judgment, Chamy Society v. Valparaiso Municipality (8th October 2019), which distinguishes different domains of the annulment and full jurisdiction action.

Keywords: Contentious action, annulment action, full jurisdiction action.

\section{Introducción}

Según Duguit, las denominaciones de acción de nulidad y de plena jurisdicción en el Derecho francés eran deficitarias, porque parecían señalar que "el juez de plena jurisdicción no puede jamás anular", mientras que el juez de anulación no podría "más que anular"1. La Sentencia de Corte Suprema Sociedad Chamy con I. Municipalidad de Valparaíso (2019) ${ }^{2}$ parece explicarse por esta circunstancia. Ella se inserta en una tendencia favorable a la distinción de acciones, según criterios y denominaciones de origen francés. No obstante, se aleja de la jurisprudencia anterior al rechazar un reclamo de ilegalidad municipal porque el actor ostentaba un derecho y no un interés.

Como en otras sentencias ${ }^{3}$, la Corte afirmará que:

[e]l reclamo de ilegalidad municipal constituye un ejemplo preciso de la acción de nulidad o "recurso por exceso de poder" (...) y no

\footnotetext{
* Profesor de Derecho Administrativo, Universidad Autónoma de Chile, Santiago, Chile. Doctor en Derecho Público, Universidad de París 1, Panthéon-Sorbonne, Francia. Correo postal: Av. Pedro de Valdivia No 641, Providencia, Santiago de Chile. Correo electrónico: pedro.harris@uautonoma.cl.

1 Duguit 1928, 473.

2 Corte Suprema Rol No 1244-2018.

${ }_{3}$ Corte Suprema Rol No 1203-2006; Corte Suprema Rol No 5288-2010; Corte Suprema. Rol N9969-2015.
}

Recibido el 3 de septiembre de 2020 y aceptado el 5 de diciembre de 2020. 
un recurso de plena jurisdicción, lo que determina que para tener legitimación activa no sea necesario invocar un derecho subjetivo lesionado, sino que basta con tener un interés legítimo ${ }^{4}$.

Esta innecesaridad, sin embargo, se convertirá luego en imposibilidad. "[A] través del presente reclamo de ilegalidad, busca el reclamante la declaración de un derecho en su favor -que no resulta propia de este tipo de procedimiento- y no la protección de un interés general" 5 .

El razonamiento de la sentencia descansaría así en dos premisas. Por una parte, el reclamo de ilegalidad municipal sería una acción de nulidad. Por la otra, la acción de nulidad supondría un interés. La conclusión es evidente. El titular de un derecho no podría ejercer el reclamo de ilegalidad municipal. La originalidad de la sentencia consistiría en clasificar estas acciones según la situación subjetiva del demandante. Así, este carecería de la facultad de elegir la vía de impugnación. Si ostenta un derecho, solo podría ejercer una acción de plena jurisdicción y, si detenta un interés, otra de nulidad; todo lo cual favorecería la supletoriedad de este último recurso ${ }^{6}$.

El lector podrá plantearse una pregunta razonable ¿Cómo entender que la Corte rechace la reclamación de ilegalidad si la propia legislación municipal integra en ella a los "particulares agraviados"?7. La respuesta parece descansar en la interpretación del díptico nulidad - plena jurisdicción. Habitualmente suele olvidarse que esta clasificación es imperfecta. Primero, ya que la plena jurisdicción integra la nulidad ${ }^{8}$. Y segundo, pues no siempre se asimila a un recurso subjetivo (que excluya intereses). La separación de criterios es comprensible de su formulación en el Derecho francés (I). Analizado ello, podrán observarse sus variaciones en nuestro país (II).

\section{La formulación de la clasificación de acciones administrativas en el Derecho francés}

La calificación francesa de acciones administrativas ha influido en diferentes ordenamientos jurídicos 9 . El Derecho chileno no ha sido una excepción. No obstante, comprender las calificaciones de estas acciones en Francia no está exenta de complejidades. Primero, ya que estas no han sido obra de un momento, sino de un movimiento constante de elaboración, crítica y reformulación. Y segundo, ya que en cada una de estas etapas se conservan rastros del pensamiento de sus autores. Esto puede observarse de la separación de cri-

\footnotetext{
4 Cons. $10^{\circ}$.

5 Cons. $13^{\circ}$.

6 A favor, véase: Bermúdez 2010, 103 y ss. Ferrada 2011, 275. En contra: Soto Kloss 2015, 73 y ss.

7 Art. 151 letra b) de la Ley $N^{\circ}$ 18.695, de 1988.

8 Esta integración ha sido afirmada desde la recepción de esta acción en el Derecho nacional. Véase: IRIBARREN 1936, 46.

9 BLANCO 2010, 31.
} 
terios, que ha opuesto una clasificación formal a otra material (1), para luego aproximar una formulación y otra (2).

\section{La separación de los criterios}

Para Laferrière, las competencias de los tribunales administrativos no tenían "la misma naturaleza y la misma extensión en todas las materias"10. Desarrollando una clasificación anticipada por Aucoc ${ }^{11}$, dicho autor distinguirá:

[P]oderes de plena jurisdicción, suponiendo el ejercicio de un arbitraje completo, de hecho y de derecho, en el litigio; o unos poderes de anulación limitados al derecho de anular los actos administrativos ilegales, sin que el juez administrativo tenga el poder de reformarlos ${ }^{12}$.

Esta dualidad se acompañaría de un poder de interpretación (discutido entre nosotros $)^{13}$ y de represión. A cada poder le correspondería una acción.

La clasificación cuadripartita de acciones de Laferrière fue aceptada, mayoritariamente, de manera bipartita, distinguiendo una acción de nulidad y otra de plena jurisdicción. Contrario a lo que podría pensarse, esta separación no opuso una acción a la otra, sino que las relacionó. La acción de plena jurisdicción comprendería el recurso de nulidad, pues la plenitud supondría anular o modificar actos, pero también reparar perjuicios. En cambio, la acción de nulidad no sería plena. Frente a ella el tribunal solo podría anular. Esta clasificación ha sido aceptada por la doctrina nacional ${ }^{14}$. No obstante, también se ha asociada a otra clasificación, formulada por Duguit.

Duguit rechazó el criterio clasificatorio de Laferrière. Por ello, el conocido positivista francés no distinguiría las acciones formalmente y en abstracto, según los poderes ejercidos por el tribunal, sino materialmente y en concreto, según la cuestión de derecho planteada. Para Duguit solo podría plantearse una cuestión de derecho objetivo o subjetivo. La cuestión será de derecho objetivo si se pregunta sobre la "vulneración de la ley" o la afectación a "una situación de derecho objetivo". En cambio, la cuestión será de derecho subjetivo si se pregunta si ha existido una afectación "a una situación de derecho subjetivo"15.

\footnotetext{
10 LAferrière 1887,15 y ss.

11 Aucoc 1869, 361 y ss.

12 LAFERRIĖRe 1887, 15 y ss.

13 Vergara 2018, 133 y ss.

14 Ferrada 2016, 327 y ss. Esta clasificación se ha conservado en la Constitución de 1925: JIRÓN et al. 1959, 64-65; NUÑEZ 1966, 116. Los autores la han formulado también durante la Constitución de 1980. Entre otros: PANTOja 2010, 695 y ss.; VAldivia 2015, 253 y ss.; Romero 2016, 209 y ss. No obstante, en la generalidad de los casos la dualidad nulidad -plena jurisdicción ha sido asociado al clasificación objetiva- subjetiva (cuestión que, si bien suele tener lugar, puede en rigor no ocurrir). Respecto de una posición diversa, que atiende a la extensión de la competencia judicial, véase: HUNTER 2014, 213.

15 Duguit 1928, 436.
} 
La situación de derecho referida por Duguit equivaldría al "conjunto de poderes y deberes reconocidos en beneficio o a la carga de un individuo"16. Si era objetiva, derivaba de la ley. Se trataría de una situación general y permanente. Si era subjetiva, derivaba de la voluntad. Se trataría de una situación especial y temporal ${ }^{17}$. Esto explicaría que la sentencia tuviera efectos absolutos en el primer caso y relativos en el segundo. En efecto, contrario a lo que podría pensarse, la calificación de acciones de Duguit no solo giraba en torno a la legitimación activa. Era una construcción compleja, que atendía a los efectos de las sentencias y del rol de las partes ${ }^{18}$.

La clasificación de acciones de Laferrière y Duguit ha tenido efectos permanentes. Para Jean-Marie Auby y Roland Drago: "La distinción de los contenciosos objetivo y subjetivo no ha sido de ninguna forma desprovista de valor práctico y cada una de las ramas que ella separa suponen ciertas particularidades en cuanto a su régimen"19. Sin embargo, los mismos autores observan "que la clasificación fundada en los poderes del juez está lejos de ser abandonada en doctrina y que, principalmente, numerosos miembros del Consejo de Estado continúan aplicándola" ${ }^{20}$. La coexistencia de tales clasificaciones se debe, sin duda, a la proximidad de los criterios.

\section{La proximidad de los criterios}

La separación de clasificaciones de acciones administrativas en Francia no ha sido absoluta. Por ello, la distinción de criterios no impidió que Duguit observara reflejada sus acciones en la formulación de Laferrière. Por un lado, el recurso subjetivo "conformaría aquello que se denomina desde hace tiempo (...) el contencioso de la plena jurisdicción" ${ }^{21}$. Por el otro, dicho autor afirmaría que la nulidad "es por cierto un recurso objetivo"22. La clasificación formal de acciones, según la competencia judicial, se asociaría así a una clasificación material, según la situación jurídica del actor. No obstante, tales criterios se asociarían precisamente porque son diversos.

La asociación de los criterios se observa en la formulación de las acciones. Este ha sido el caso del recurso objetivo de plena jurisdicción. Ignorado

\footnotetext{
16 Melleray 2001, 76.

17 Duguit 1927, 308-315.

18 Melleray 2001, 83.

19 Auby y Drago 1992, 12.

20 ĺdem.

21 Duguit 1928, 473.

22 Ibíd., 468. De hecho, para el conocido tratadista francés esta también habría sido la situación de las acciones de responsabilidad. En principio, ellas se asociarían a un interés. El derecho solo nacería en la fase de ejecución o condena. Esta interpretación ha sido ampliamente limitada. Primero, por la asociación de la responsabilidad a un recurso objetivo, solo respecto de derechos que emanen directamente en la legislación. Véase: AuBY y DRAGo 1992, 12. Y, en segundo lugar, pues otros autores sustituyen la clasificación de "recursos" objetivos y subjetivos por la clasificación de "contenciosos" de un carácter u otro. Esto permite superar la dificultad de distinguir las situaciones de derecho, a favor de procesos (o contenciosos) centrados en la legalidad (objetivos) o en la responsabilidad (subjetivos). Véase: BAILleul 2002, 16.
} 
en la jurisprudencia nacional, este recurso en el Derecho francés le otorga competencias al juez para atender la situación de un demandante, a través del ejercicio de competencias que van más allá de la nulidad, sin alcanzar la responsabilidad ${ }^{23}$. Esta formulación ilustra sobre la amplitud del concepto de plena jurisdicción, que integra diferentes facultades jurisdiccionales, distinguibles de la sola reparación de perjuicios. Paralelamente, muestra cómo estas acciones pueden asociarse a un interés.

La asociación de los criterios se aprecia también en la recalificación de las acciones. Esta recalificación opera en el marco de la formulación de una acción de nulidad (conocida en Francia como un recurso de exceso de poder). Dicho recurso ha sido consagrado desde el siglo XIX. No obstante, solo desde mediados del siglo XX se ha aceptado, sin necesidad de un texto expreso que funde su procedencia -Sentencia del Consejo de Estado Dame Lamotte (1950)-. La circunstancia que esta acción de nulidad pudiera ejercerse sin apoyo de un texto, llevó a plantear en su oportunidad la forma cómo debía articularse con otros recursos contenciosos.

Esta asociación se relaciona con el criterio seguido por la jurisprudencia nacional. Contrario a lo que la Sentencia Sociedad Chamy con I. Municipalidad de Valparaíso (2019) propone, en el Derecho francés el recurso de nulidad y el de plena jurisdicción son intercambiables. Por regla general el actor puede elegir si ejercer uno u otro. Tal liberalidad ofrece ventajas. La sustitución de la nulidad por el recurso de plena jurisdicción permitirá declarar la responsabilidad de la Administración, una vez extinta aquella acción por efecto del tiempo ${ }^{24}$. La sustitución de la plena jurisdicción por el recurso de nulidad permitirá librarse del costo del patrocinio de abogado.

La dificultad ocurrirá si el acto impugnado tiene un contenido pecuniario. Desde la Sentencia del Consejo de Estado Lafage (1912), el actor, si solo demanda la nulidad, puede ejercer un recurso de nulidad o de plena jurisdicción. No obstante, la Sentencia del Consejo de Estado Lafon (1959) limitó esta elección. Si se acciona vía un recurso de plena jurisdicción, deberá interponerse en el plazo para ejercer la acción de nulidad (de dos meses), salvo que demande perjuicios distintos a la devolución pecuniaria. De lo contrario, se entenderá que ejerce esta acción de manera extemporánea ${ }^{25}$. Como se verá, dicho criterio ha influenciado a nuestra jurisprudencia.

\section{La importación de la clasificación de acciones administrativas en el Derecho nacional}

El sabido que el Derecho nacional ha carecido de una clasificación original de acciones administrativas. Esto podría explicar en parte la influencia del Derecho francés. Diferentes autores nacionales han distinguido entre accio-

\footnotetext{
23 Lepetit-Collin 2011, 10; Valdivia 2015, 253 y ss.

24 Gaudemet 2015, 150.

25 Broyelle 2017-2018, 66.
} 
nes de nulidad y de plena jurisdicción ${ }^{26}$. Esta distinción ha encontrado apoyo en la jurisprudencia. Desde la Sentencia Eyzaguirre Cid con Fisco (2007), el recurso de plena jurisdicción ha sido recepcionado para recalificar la acción de nulidad. Aunque esta recalificación opera conforme a la pretensión (1), la sentencia comentada adopta una posición distinta, calificando la acción de plena jurisdicción según la legitimación (2).

\section{La identificación de la acción conforme a la pretensión}

La Sentencia de Corte Suprema Aedo con Fisco (2000) inauguró una distinción de acciones que, aunque conocida en el Derecho privado, era desconocida en el Derecho administrativo. Este fue el resultado de distinguir entre acciones de nulidad, de responsabilidad y reivindicatorias. Aunque dicha enumeración no obedece a un criterio clasificatorio, el aporte de esta sentencia fue desvincular la nulidad de ciertos efectos jurídicos que ella podría originar consecuencialmente, al sujetarse a estatutos diversos. Mientras que la nulidad sería imprescriptible, algunos de sus efectos podrán prescribir. Sobre esta base, esta distinción sería influenciada por el Derecho francés, en su operatividad y denominación.

La influencia sobre la operatividad de las acciones tendría lugar mediante la recalificación del recurso contencioso. Bajo la influencia de la recalificación de acciones del Consejo de Estado francés (pero operando en el sentido inverso $)^{27}$, la jurisprudencia Eyzaguirre Cid con Fisco (2007) inició esta tendencia, que se conserva hasta hoy ${ }^{28}$. Si el actor demanda la nulidad de un acto con contenido patrimonial, la Corte asimilará el efecto retroactivo de la anulación a la reparación de perjuicios del recurso plena jurisdicción. Por ello, tal acción sería susceptible de extinguirse tras cinco años luego que la obligación fuera exigible (arts. 2514 y 2515 del Código Civil).

La influencia sobre la denominación de las acciones tendría lugar para calificar dicha recalificación de recursos contenciosos. En efecto, si bien la Sentencia Eyzaguirre Cid con Fisco siguió a la jurisprudencia francesa materialmente, no utilizó la calificación formal de sus acciones. La jurisprudencia que utilizaría esta denominación para recalificar tales recursos será la Sentencia de Corte Suprema Droguet con Ejercito (2013). Aunque la denominación de plena jurisdicción ya se encontraba en la jurisprudencia del máximo tribu-

\footnotetext{
26 Pantoja 2010, 695 y ss.; Hunter 2014, 213; Ferrada 2016, 321 y ss.; Romero 2016, 209 y ss.; VERGARA 2018, 61 y ss.

27 En el Derecho francés, la recalificación opera del recurso de plena jurisdicción al recurso de nulidad (exceso de poder). En cambio, en el Derecho chileno, la recalificación opera del recurso de nulidad al recurso de plena jurisdicción.

28 Sentencia de Corte Suprema Rol No3689-2006; Sentencia de Corte Suprema Rol N²8582008; Sentencia de Corte Suprema Rol N5288-2010; Sentencia de Corte Suprema No Rol 88672012; Sentencia de Corte Suprema Rol N²3434-2014; Sentencia de Corte Suprema $N^{\circ}$ Rol 32132-2014; Sentencia de Corte Suprema Rol No 715-2015; Sentencia de Corte Suprema Rol No 41987-2017; Sentencia de Corte Suprema Rol No 8484-2018; Sentencia de Corte Suprema Rol N 15489-2018; Sentencia de Corte Suprema Rol N 7410-2019.
} 
nal29, la Sentencia Droguet con Ejercito caracterizó la legitimación, los efectos y la extinción de esta acción, siguiendo al país galo.

La primera característica de esta recalificación se asocia a su causa. Ella ha sido utilizada para limitar temporalmente la nulidad (mas no aspectos como la legitimación activa o los efectos de la sentencia). Si la nulidad se recalifica como una plena jurisdicción habrá dos tendencias. Una que afecta a la acción (mayoritaria) y otra que incide en su eficacia (minoritaria). La primera impone que el recurso deba ejercerse en el plazo de cinco años desde que la obligación es exigible -Sentencia de Corte Suprema Eyzaguirre Cid con Fisco-. En cambio, la segunda admite un ejercicio posterior, limitando sus efectos -Sentencia de Corte Suprema INP con Cuello (2007) ${ }^{30}$.

La segunda característica de esta recalificación se asocia a sus efectos. Con ocasión de una recalificación de acciones, la jurisprudencia introdujo en rigor una reclasificación. No obstante, de manera descontextualizada del sentido atribuido por la doctrina nacional ${ }^{31}$. Ello ha generado una relativa incomprensión de los criterios. En particular por la difícil operatividad que supone articular el ejercicio de estos recursos. Frente a la sofisticación que implica combinar la acción de nulidad y de plena jurisdicción, la recalificación aparece, paradojalmente, como el hermano mayor de su calificación. Así se observa de la dificultad de identificar cada acción.

\section{2. ¿La identificación de la acción conforme a la legitimación?}

Desde la Sentencia Eyzaguirre Cid con Fisco, la afirmación de un recurso de plena jurisdicción ha tenido por finalidad limitar los efectos de la retroactividad de la nulidad, mediante la aplicación del art. 2515 del Código Civil. Esta recalificación operaría in concreto, a condición que el acto tenga un contenido patrimonial. La Sentencia Sociedad Chamy con I. Municipalidad de Valparaíso adopta un criterio diverso. El recurso de plena jurisdicción se calificaría conforme a la legitimación activa del demandante. Esta calificación operaría in abstracto. Así, toda protección de derechos deberá operar a través de una acción distinta a la nulidad, de plena jurisdicción.

No es posible afirmar que esta posición sea intempestiva. Ella ha sido anunciada en diferentes fallos que califican el reclamo de ilegalidad municipal como una acción de nulidad ${ }^{32}$. El fundamento de esta calificación se ha centrado en la legitimación activa. Esta posición ha sostenido que dicho recurso no requeriría de la vulneración de un derecho, sino de un interés. La Sentencia Sociedad Chamy con I. Municipalidad de Valparaíso razona a contrario sensu a partir de esta asociación, asimilando el criterio formal (nulidad

\footnotetext{
29 Ferrada 2016, 333. A propósito de la Sentencia de Corte Suprema Rol N³79-2004.

30 Véase: Sentencia de Corte Suprema Rol N³689-2006.

31 FerRada 2016, 321 y ss.

32 V. gr.: Sentencia de Corte Suprema Rol No 1203-2006; Sentencia de Corte Suprema Rol No 5288-2010; Sentencia de Corte Suprema Rol N 9969-2015; Sentencia de Corte Suprema Rol $N^{\circ} 34588-2017$.
} 
- plena jurisdicción) a otro material (objetivo - subjetivo). Al amalgamar distintas clasificaciones de acciones, ello podría cuestionarse.

El primer cuestionamiento se asocia a la definición de la nulidad. En rigor, este efecto es común a las acciones de nulidad y de plena jurisdicción. Por ello, puede demandarse por un interesado o un titular de un derecho. Esto es así porque, si la plena jurisdicción va más allá de la anulación, lógicamente la comprende. Sin perjuicio que algunas sentencias lo afirmen ${ }^{33}$, esto se aprecia en la propia jurisprudencia, que recalifica la acción de nulidad como una plena jurisdicción, si la acción supone el ejercicio de derechos patrimoniales. Si la jurisprudencia recalifica la acción de nulidad como una plena jurisdicción ¿cómo excluir de aquella al titular de derechos?

El segundo cuestionamiento deriva de la definición de la plena jurisdicción. En nuestro país (a diferencia del Derecho francés) dicha acción no ha sido calificada como tal en Derecho positivo ${ }^{34}$. $Y$, salvo que se asimile a una acción de responsabilidad, solo podría definirse objetivamente, según la competencia judicial. Paradojalmente, este es el caso del reclamo de ilegalidad municipal. Según el art. 151 h) de la Ley N 18.695, de Municipalidades, la Corte puede anular un acto o modificarlo, e incluso reparar perjuicios. Si la jurisprudencia acoge la clasificación de acciones de nulidad y de plena jurisdicción, el reclamo de ilegalidad pertenecería a estas últimas ${ }^{35}$, siendo su legitimación activa variable.

La Sentencia Sociedad Chamy con I. Municipalidad de Valparaíso plantea incertezas sobre la clasificación de acciones administrativas utilizada por la jurisprudencia. Al mismo tiempo, lleva a preguntarse si la recepción del concepto de plena jurisdicción es adaptable en nuestro derecho que, a diferencia del francés, denomina a la acción de nulidad por su efecto (como nulidad) y no por su causa (como exceso de poder). Esta separación es inexacta $^{36}$, pues dejar sin efecto retroactivamente un acto ilegal (anular) es un mínimo de jurisdicción. Qui potest plus, potest minus. Si el titular de un interés puede demandar la nulidad, el titular de un derecho también.

\footnotetext{
33 Sentencia de Corte Suprema Rol Nº 10639-2013.

34 VALDIVIA 2018, 380.

35 HUNTER 2014, 213. De hecho, la calificación de plena jurisdicción del reclamo de ilegalidad municipal se observa en la sentencia que introduce la distinción de este recurso con la acción de nulidad: Sentencia de Corte Suprema Rol N³79-2004 cons. 11º: "que el criterio restrictivo de la competencia del órgano jurisdiccional en el conocimiento y fallo de los reclamos de ilegalidad, sustentado por la sentencia recurrida, que no los considera medios idóneos para impugnar la legalidad de las resoluciones emanadas de entidades públicas, como las Municipalidades -según se dejó expresado en el considerando primero-, carece de asidero jurídico tanto por tratarse en la especie de un recurso contencioso administrativo de plena jurisdicción (...) como por la regulación positiva de dicho arbitrio".

36 Auby y Drago (1984), 80, citado en: Bailleul 2002, 18.
} 


\section{Conclusión}

El que la acción de nulidad pueda ejercerla un interesado (y no requiera de la afectación de un derecho) ha llevado a asimilarla a un recurso contencioso objetivo. Paralelamente, el que la acción de plena jurisdicción suela acarrear una reparación patrimonial ha llevado a vincular su ejercicio a la titularidad de un derecho y, con ello, a una calificación subjetiva. La sentencia aquí comentada extrae una consecuencia de tales asimilaciones: el titular de un derecho carece de una acción de nulidad, debiendo ejercer un recurso de plena jurisdicción.

Así entendida, cabrá preguntarse qué tan plena es la acción de plena jurisdicción. En efecto, la separación entre un recurso contencioso de nulidad y otro de plena jurisdicción es inexacta pues, para que una acción contenciosa sea plena, es necesario que al tribunal pueda anular los actos de la Administración en contra de los cuales se ejerce. Esto explica que la plena jurisdicción solo pueda entenderse referida a aquellos recursos contenciosos que, además de facultar para anular actos, permitan modificarlos y/o reparar perjuicios.

Paradojalmente, este es el caso del reclamo de ilegalidad municipal, que faculta a la Corte de Apelaciones para anular el acto, modificarlo y reparar los perjuicios, pudiendo ejercerlo cualquier particular o aquellos agraviados (art. 151 de la Ley $N^{\circ}$ 18.695, letras a y b). Calificar como una nulidad la reclamación de cualquier particular es inexacto, pues podrá demandar también la modificación del acto. Calificar de plena jurisdicción un reclamo en que el agraviado no puede demandar la nulidad resulta impropio, no solo porque la reclamación carecería de plenitud, sino (y sobre todo) porque la ley lo faculta para hacerlo.

\section{Bibliografía}

Auby, J.M. y Drago, R. (1984). Traité de contentieux administratif. LGDJ.

Auby, J.M. y Drago, R. (1992). Traité des recours en matière administrative. Litec.

Aucoc, L. (1869). Conférences sur l'administration et le droit administratif (T I). Dunod.

Bailleul, D. (2002). L'efficacité comparée des recours pour excès de pouvoir et de plein contentieux objectif en droit public français. LGDJ.

Bermúdez, J. (2010). Estado actual del control de legalidad de los actos administrativos: ¿qué queda de la nulidad de derecho público? Revista de derecho (Valdivia), 23 (1), $103-123$.

Blanco, F. (2010). Pouvoirs du juge et contentieux administratif de la légalité - Contribution à l'étude de l'évolution et du renouveau des techniques juridictionnelles dans le contentieux de l'excès de pouvoir. Presses Universitaires Aix-Marseille.

Broyelle, C. (2017). Contentieux administratif (5 $5^{\text {e }}$ ed.). LGDJ.

Duguit, L. (1927). Traité de droit constitutionnel (3a ed.) (T I). Ancienne Librairie Fontemoing et Cie.

Duguit, L. (1928). Traité de droit constitutionnel ( $3^{\mathrm{a}}$ ed.) (T II). Ancienne Librairie Fontemoing et Cie.

Ferrada, J. (2011). "Los procesos administrativos en el Derecho chileno". Revista de Derecho de la Pontificia Universidad Católica de Valparaíso (36), 251-277.

Ferrada, J. (2016). La clasificación de los recursos o acciones contencioso - administrativas en el Derecho Administrativo chileno: la influencia de la doctrina francesa en nuestro 
derecho y su aplicación jurisprudencial. En O. Urrutia et al. (coord.), Doctrina y enseñanza del derecho administrativo chileno: Estudios en homenaje a Pedro Pierry Arrau (pp. 321-341). Ediciones Universitarias de Valparaíso.

Gaudemet, Y. (2015). Droit administratif (21 $1^{\mathrm{a}}$ ed.). LGDJ.

Hunter, I. (2014). Reclamo de ilegalidad municipal en la jurisprudencia: caos interpretativo y criterios dudosos. Revista de derecho (Valdivia), 27(2), 191-215.

Iribarren, J. (1936). Lecciones de Derecho administrativo. Editorial Nascimiento.

Jirón, E. et al. (1959). Lo contencioso-administrativo. Editorial Jurídica de Chile.

Laferrière, É. (1887). Traité de la juridiction administrative et des recours contentieux (T I). Berger-Levrault et Cie.

Lepetit-Collin, H. (2011). Recherches sur le plein contentieux objectif. LGDJ.

Melleray, F. (2001). Léon Duguit et Georges Scelle. Revue d'histoire des facultés de droit et de la culture juridique, du monde des juristes et du livre juridique (21), 45-88.

Núñez, J. C. (1966). Recursos jurisdiccionales y administrativos especiales. Alcázar y Sacaluga.

Pantoja, R. (2010). El artículo 38 inciso $2^{\circ}$ de la Constitución Política de la República. En R. Tavolari (coord.), Doctrinas esenciales - Derecho Constitucional, pp. 695-714. Editorial Jurídica de Chile.

Romero, A. (2016). Unos problemas del derecho al recurso en el contencioso ambiental. Cuadernos de extensión jurídica de la U. de Los Andes (28), 2016, 209-222.

Soto Kloss, E. (2015). La nulidad de derecho público según la Corte Suprema de hoy: de su tergiversación a su destrucción. lus publicum (34), 73-92.

Valdivia, J. M. (2015). Contenido y efectos de las sentencias de los Tribunales Ambientales. En J. C. Ferrada et al. (coord.), La nueva justicia Ambiental, pp. 253-276. Legalpublishing.

Valdivia, J. M. (2018). Manual de Derecho administrativo. Tirant lo blanch.

Vergara, A. (2018). Derecho administrativo: Identidad y transformaciones. Ediciones UC.

\section{Normas citadas}

Constitución Política de la República de Chile [Const]. 17 de septiembre de 2005 (Chile).

Decreto $\mathrm{N}^{\circ} 1$ de 2000 [con fuerza de ley]. Fija el texto refundido, coordinado y sistematizado del Código Civil; de la Ley $\mathrm{N}^{\circ} 4.808$, sobre registro civil, de la Ley $\mathrm{N}^{\circ} 17.344$, que autoriza cambio de nombres y apellidos, de la Ley $N^{\circ} 16.618$, ley de menores, de la Ley $N^{\circ} 14.908$, sobre abandono de familia y pago de pensiones alimenticias, y de la Ley $\mathrm{N}^{\circ} 16.271$, de impuesto a las herencias, asignaciones y donaciones. 16 de mayo de 2000. D.O. No 36.664.

Decreto $\mathrm{N}^{\circ} 1$ de 2006 [con fuerza de ley]. Fija el texto refundido, coordinado y sistematizado de la Ley $N^{\circ} 18.695$, Orgánica constitucional de Municipalidades. 9 de mayo de 2006. D.O. No 38.458.

\section{Jurisprudencia citada}

Consejo de Estado francés. No 42612, 8 marzo 1912.

Consejo de Estado francés. N ${ }^{\circ} 86949,17$ febrero 1950.

Consejo de Estado francés. No 44419, 2 mayo 1959.

Corte Suprema. Tercera Sala Constitucional. Rol 379-2004, 20 de octubre 2004.

Corte Suprema. Tercera Sala Constitucional. Rol 1203-2006, 28 junio 2007.

Corte Suprema. Tercera Sala Constitucional. Rol 3689-2006, 30 agosto 2007.

Corte Suprema. Tercera Sala Constitucional. Rol 5288-2010, 27 enero 2009.

Corte Suprema. Tercera Sala Constitucional. Rol 2858-2008, 23 marzo 2010.

Corte Suprema. Tercera Sala Constitucional. Rol 5288-2010, 4 enero 2013.

Corte Suprema. Tercera Sala Constitucional. Rol 8867-2012, 8 abril 2013.

Corte Suprema. Tercera Sala Constitucional. Rol 10639-2013, 30 enero 2014.

Corte Suprema. Tercera Sala Constitucional. Rol 32132-2014, 24 agosto 2015. 
Corte Suprema. Tercera Sala Constitucional. Rol 715-2015, 14 mayo 2015.

Corte Suprema. Tercera Sala Constitucional. Rol 23434-2014, 23 abril 2015.

Corte Suprema. Tercera Sala Constitucional. Rol 9969-2015, 17 mayo 2016.

Corte Suprema. Tercera Sala Constitucional. Rol 41987-2017, 31 julio 2018.

Corte Suprema. Tercera Sala Constitucional. Rol 34588-2017, 31 mayo 2018.

Corte Suprema. Tercera Sala Constitucional. Rol 15489-2018, 4 septiembre 2019.

Corte Suprema. Tercera Sala Constitucional. Rol 1244-2018, 8 octubre 2019.

Corte Suprema. Tercera Sala Constitucional. Rol 8484-2018, 2 mayo 2019.

Corte Suprema. Tercera Sala Constitucional. Rol 7410-2019, 28 mayo 2020. 
